\title{
UMA ANÁLISE DO ORÇAMENTO OPERACIONAL
}

Stefano José Caetano SILVEIRA *

*Economista, Mestre em Economia do Desenvolvimento (PPGE-UFRGS), Administrador Orçamentário da Procergs. stefano-silveira@ procergs.rs.gov.br

\section{Recebido em: 28/01/2015 - Aprovado em: 18/06/2015 - Disponibilizado em: 15/07/2015}

\begin{abstract}
Resumo
A proposta deste artigo foi apresentar uma análise do orçamento operacional, abordando suas origens, seus principais instrumentos no setor público, bem como, em linhas gerais, suas fases de elaboração, implantação, operacionalização e consolidação, permitindo vislumbrar sua contribuição à instituição que o adote no tocante à rentabilidade e à lucratividade. Para tanto, efetuou-se uma breve revisão da bibliografia existente sobre o tema, além de uma pesquisa abrangente sobre as etapas a serem vencidas até que o orçamento seja posto em prática. Com base nesse arcabouço, buscou-se definir a importância dessa ferramenta para as instituições, passando pela premência de sua difusão e compreensão por parte do corpo funcional, por sua correta empregabilidade e operacionalidade (sob o risco de distorção dos resultados), chegando à avaliação dos benefícios alcançados.
\end{abstract}

Palavras-chave: Orçamento Operacional. Planejamento. Resultado.

\section{AN ANALYSIS OF OPERATING BUDGET}

\begin{abstract}
The purpose of this paper was to present an analysis of the operational budget, discussing its origins, its main instruments in the public sector, as well as, in general, their stages of development, deployment, operation and consolidation, allowing envision their contribution to the institution which adopts regarding the profitability and profitability. To do so, we performed a brief review of existing literature on the subject, plus a comprehensive research about the steps to be overcome until the budget is put in place. Based on this framework, we sought to define the importance of this tool for institutions, through the urgency of dissemination and understanding on the part of the staff, for their correct operation and employability (at the risk of distorting the results), coming to avaliation the benefits achieved.
\end{abstract}

Keywords: Operating Budget. Planning. Result.

\section{Introdução}

Nos dias atuais, o mercado é impulsionado pelo avanço tecnológico aliado ao aprimoramento dos recursos humanos e materiais. Dessa forma, torna-se imperativo para as organizações saberem se adaptar às novas situações, sob risco de deixarem de existir. Para que essas adaptações sejam bemsucedidas, as atividades devem estar planejadas de forma satisfatória, bem como os objetivos e as metas definidas 
de forma clara tanto em relação à sua compreensão como em sua execução. Nesse particular, a concepção e utilização de um orçamento tornam-se peça chave (ZDANOWICZ, 1986).

O orçamento pode ser compreendido como uma ferramenta de ação, devido à sua propriedade de auxílio e orientação quando da tomada de decisões da instituição. Aliando dados e informações de situações passadas no âmbito organizacional com variáveis externas que podem - direta ou indiretamente - afetá-la, o orçamento emprega uma gama de conhecimentos multidisciplinares, envolvendo ciências econômicas, administrativas, contábeis e estatísticas, tornando-se um sistema. E é justamente esse sistema que permite a condução, de forma ordenada e racional, das ideias e das ações, possibilitando a organização ultrapassar etapas, como se fosse, na visão de Zdanowicz (1986), a superação dos degraus de uma escada.

Os dois primeiros degraus podem ser entendidos como o planejamento das atividades operacionais e o controle que permite a análise e a comparação dos resultados obtidos. Ambos devem estar em consonância à execução do planejamento, permitindo correções de rumo, tendo em vista a constante busca por melhores resultados. Cabe ressaltar que o grau de detalhamento de o planejamento e controle poderá variar de acordo com o porte da empresa e de seu tipo de atividade, bem como de suas necessidades. Ao constatar que as relações com os consumidores, fornecedores, acionistas e concorrentes exercem grande importância para a organização, sugerindo a necessidade de um planejamento sistemático, tem-se o momento exato da implantação de um sistema orçamentário operacional (FUROBOTN; RICHTER, 2000; ZDANOWICZ, 1986).

Portanto, a intenção deste artigo é apresentar uma análise do orçamento operacional, abordando suas fases de elaboração, implantação, operacionalização e consolidação, bem como sua contribuição para que as instituições atinjam os resultados desejados no tocante à rentabilidade $\mathrm{e}$ lucratividade. Dessa forma, buscou-se definir a importância dessa ferramenta, passando pela premência de sua difusão a todo o corpo funcional, por sua correta empregabilidade e operacionalidade, sob o risco de distorção dos resultados, 
chegando à avaliação dos benefícios alcançados.

\section{As Origens do Orçamento e sua}

\section{Evolução Através do Tempo}

Por volta de 1822, auge do liberalismo, o orçamento público surgiu na Inglaterra. Nessa época havia uma preocupação com o crescimento das despesas públicas e com a participação do Estado. Esse orçamento, chamado de tradicional, tinha como principal função disciplinar as finanças e possibilitar aos órgãos de representação o controle político sobre o Executivo. As contas nacionais caracterizavam-se pela neutralidade. Ou seja, o orçamento tinha como mecanismo base apenas $\mathrm{o}$ empenho de verbas (VASCONCELLOS; GARCIA, 2008).

Assim como o setor público, as empresas privadas, acuadas pelo crescimento das atividades mercadológicas e pelo acirramento da concorrência, viram-se obrigadas a estabelecer - a curto e médio prazo uma rotina para suas atividades, visando poder orçar os resultados a serem perseguidos. Nesse instante, o orçamento passou a ser utilizado como instrumento de planejamento e controle nas organizações particulares. O pioneirismo do uso da técnica orçamental em uma companhia privada é atribuído ao norteamericano Donaldson Brown, gerentefinanceiro da Du Pont De Memours. Sua adoção, em 1919, permitiu à empresa suportar a crise de $1921^{1}$, ao contrário da General Motors, que por não estar preparada, sofreu com os seus efeitos. Por outro lado, as companhias brasileiras começaram a empregar, mesmo que de forma incipiente, a técnica orçamentária na década de 1950. Porém, somente a partir dos anos 1970 é que as empresas nacionais perceberam a necessidade de planejar e controlar suas atividades (ZDANOWICZ, 1986).

Segundo Vasconcellos e Garcia (2008), baseado no pensamento keynesiano, a partir da década de 1930 o Estado abandonou a neutralidade econômica e passou a tentar corrigir as distorções financeiras e estimular programas de desenvolvimento. Tal situação pode ser ilustrada pelo lançamento do New Deal, do presidente

\footnotetext{
${ }^{1}$ Entre novembro de 1919 e agosto de 1921, os Estados Unidos viveram um embrião da crise de 1929 que se avizinhava. O índice Dow Jones caiu pela metade, a taxa de desemprego dobrou, houve deflação de quase $20 \%$ e o PIB declinou $6,9 \%$. Todavia, houve uma rápida recuperação, dado no final de 1922 a economia já apresentar níveis pré-recessão.
} 
norte-americano Franklin Delano

Roosevelt (1933-1945), como uma resposta ao crash de 1929. A função de instrumento administrativo é aperfeiçoada no orçamento a partir desse momento, tornando-o um instrumento de aferição e fixação das propriedades no planejamento global dos governos, surgindo assim os chamados princípios orçamentários, que podem ser classificados como: princípio da unidade, da universalidade, do orçamento bruto, da anualidade, da nãovinculação das receitas, da discriminação ou especialização, da exclusividade e do equilíbrio.

$\mathrm{O}$ princípio da unidade determina que cada entidade pública financeiramente autossuficiente deve possuir apenas um orçamento. Tais entidades são as que não têm suas receitas e despesas agregadas no orçamento central. Como exemplos podem ser citados a previdência e as estatais. O princípio da universalidade designa que o orçamento do Estado necessita conter todas suas receitas e despesas $^{2}$. Já o princípio do orçamento

\footnotetext{
${ }^{2}$ Caso surjam receitas ou despesas inesperadas ao longo do período, que não estejam previstas no orçamento, serão consideradas extraorçamentárias.
}

bruto afirma que as parcelas da receita e despesas contidas no orçamento não devem ter qualquer dedução, ou seja, os valores lá constantes devem ser brutos. $\mathrm{O}$ orçamento deve ser elaborado para determinado período de tempo, normalmente um ano, diz o princípio da anualidade. É comum o ano orçamentário acompanhar o período de funcionamento do Legislativo (VASCONCELLOS; GARCIA, 2008).

O princípio da não-vinculação das receitas impede que elas, mesmo parcialmente, sejam vinculadas a determinados gastos $^{3}$. O princípio da discriminação ou especialização avalia que as receitas e as despesas devem constar no orçamento de maneira discriminada, visando à clareza da origem e a destinação dos recursos. Por sua vez, o princípio da exclusividade exige que o orçamento deva conter exclusivamente matérias de natureza orçamentária. Por fim, o princípio do equilíbrio. A diferença entre o orçamento tradicional e o moderno reside nesse princípio. Enquanto para os economistas clássicos o equilíbrio

\footnotetext{
${ }^{3}$ Nada impede que uma parcela do montante da receita esteja vinculada a uma despesa. O que não é permitido, é que a receita oriunda de uma fonte (cliente ou contribuinte) esteja vinculada (total ou parcialmente) a determinado gasto.
} 
orçamentário é fundamental, devendo um eventual déficit público ser coberto com recursos produtivos, a partir dos anos 1930, a escola heterodoxa avalia que o gasto público pode ter um papel estabilizador na economia ${ }^{4}$. Esse cenário pode ser constatado durante a chamada "síntese neoclássica". (VASCONCELLOS; GARCIA, 2008).

\section{Orçamento Público no Brasil}

De acordo com Vasconcellos e Garcia (2008), no Brasil a elaboração do orçamento público segue os passos determinados pela Constituição Federal de 1988 e seus dispositivos posteriores, como as Propostas de Emendas

\footnotetext{
4 Durante o ano de 2005, o ex-ministro da Fazenda Delfim Netto passou a defender com veemência a necessidade de o país produzir o "déficit nominal zero". Segundo ele, tornava-se necessário "eliminar" as vinculações de receitas do orçamento com várias formas de dispêndio de muitos ministérios, como o da Saúde e Educação, mesmo que isso viesse a gerar queda de repasse a esses ministérios (Fonte: O Estado de São Paulo).

${ }^{5}$ Movimento acadêmico que procurou conciliar o pensamento de John Maynard Keynes com as ideias da escola neoclássica. A economia empregada, sobretudo após o final da II Guerra Mundial, em 1945, passou a ser keynesiana em macroeconomia e neoclássica em microeconomia. $\mathrm{O}$ processo iniciou após a publicação da obra "A Teoria Geral do Emprego, do Juro e da Moeda" de Keynes, em 1936, com o Modelo IS/LM exercendo um papel de protagonismo. A lei da oferta e demanda foram adaptadas para os modelos de mercado da teoria keynesiana, fazendo com que os incentivos e custos tivessem um papel fundamental na tomada de decisão.
}

Complementares (PECs) surgidas após sua promulgação. $\mathrm{O}$ executivo, por meio de lei, estabelece: 1) o plano plurianual (PPA) ${ }^{6}$; 2) a lei de diretrizes orçamentárias (LDO); e 3) orçamentos anuais.

O PPA estabelece as diretrizes, objetivos e multas da administração pública federal para as despesas de capital e outras delas decorrentes e para as relativas aos programas de duração continuada, tudo de forma regionalizada. Já a LDO abrange as metas e as prioridades da administração pública federal, englobando nisso as despesas de capital para o próximo exercício financeiro. Além disso, dispõe sobre as alterações na legislação tributária e as diretrizes das agências de fomento (VASCONCELLOS; GARCIA, 2008).

\section{A lei orçamentária anual} compreende três grandes grupos, assim

\footnotetext{
${ }^{6}$ Os dois tipos básicos de planejamento são o de curto e de longo prazo. O primeiro compreende um período de seis meses a um ano e abrange o controle das atividades operacionais da instituição, dado conter informações para decisões rotineiras, visando o melhor emprego dos recursos físicos e monetários. Já o último, refere-se às decisões estratégicas que buscam planejar os recursos necessários, informar as fontes de financiamento e melhorar a alocação do investimento planejado. Isso por ser representado pela instalação de novas unidades industriais ou filiais ou pela ampliação e modernização das atividades econômicofinanceiras (ZDANOWICZ, 1986).
} 
definidos na Constituição Federal Brasileira, Título VI, artigo 165, parágrafo $5^{\circ}$ :

I o orçamento fiscal referente aos Poderes da União, seus fundos, órgãos e entidades da administração direta e indireta, inclusive

fundações instituídas e mantidas pelo poder público;

II o orçamento de investimento das empresas em que a União, direta ou indiretamente, detenha a maioria do capital social com direito a voto;

III o orçamento da seguridade social, abrangendo todas as entidades $\mathrm{e}$ órgãos a ela vinculados, da administração direta ou indireta, bem como os fundos $\mathrm{e}$ fundações instituídos mantidos pelo poder público.

\section{O Orçamento Geral da União}

(OGU) é formado pela soma do Orçamento Fiscal, do Orçamento de Investimento das Empresas Estatais Federais e do Orçamento da Seguridade
Social, além das "renúncias ficais". Os projetos de lei relativos ao plano plurianual, às diretrizes orçamentárias, ao orçamento anual e aos créditos adicionais são apreciados tanto pela Câmara dos Deputados como pelo Senado Federal na forma de regimento comum, que os devolverão ao Executivo para sanção ou veto. Além disso, existem prazos específicos para cada lei e cada etapa do processo (MACHADO, 2002; VASCONCELLOS; GARCIA, 2008). Por fim, a Lei de Responsabilidade Fiscal (LRF), que é um importante instrumento de política fiscal implementado a partir de 1998, busca propiciar o equilíbrio orçamentário do setor público. Suas principais atribuições são: limite para as despesas com funcionalismo público de $50 \%$ para União e $60 \%$ para estados e municípios; proibição de socorros financeiros entre União, estados e municípios; limite de despesas feitas pelos gestores públicos em final de mandato; e limites de endividamento para União, estados e municípios, por meio do Senado. Caso as administrações venham a não cumprir essa lei, poderão perder o direito de repasse de verbas da 
União $^{7}$. Além disso, os responsáveis podem sofrer sanções por crimes de responsabilidade fiscal. Com a LRF, ganhou-se maior eficiência na ação governamental, obrigando estados e municípios a explorar mais as receitas próprias, contribuindo decisivamente para o ajuste fiscal (VASCONCELLOS; GARCIA, 2008).

Por conta desse planejamento e controle, constatam-se ganhos como redução de custos e transparência para a gestão pública como um todo.

\section{Um Modelo de Orçamento} Operacional para Empresa de Grande Porte Brasileira

Podendo ser definido como uma importante ferramenta para o sucesso da organização, o orçamento operacional remete aos objetivos que se aspira alcançar. Assim, tal ferramenta tornou-se imperiosa no intuito de alocar, da forma mais eficiente possível, os recursos da instituição. Através dele, oportunidades identificadas que venham a resultar em um satisfatório retorno ao capital disponibilizado são contempladas.

\footnotetext{
7 Por exemplo, o Imposto sobre Produtos Industrializados (IPI) e o Imposto de Renda (IR) arrecadados pela União e parcialmente repassados aos estados e municípios.
}

Conforme já citado, a concepção do orçamento vem ganhando importância no Brasil desde a década de 1970. Em uma de suas formas mais tradicionais, as previsões entre a receita e a despesa são agrupadas por setores (também chamados de departamentos ou divisões), passando pelo controle através da adoção de planilhas eletrônicas individuais ou de uma grande planilha que comporta diversas abas, cada uma representando um segmento orçamentário da organização.

Passa-se agora a uma análise individual sobre as etapas do planejamento da empresa, dividindo a citada análise em três grandes grupos: elaboração e implantação, operacionalização e consolidação.

\subsection{Elaboração e Implantação}

A elaboração de um orçamento operacional passa por alguns prérequisitos. Seu conteúdo deve estar alinhado ao planejamento estratégico da instituição ${ }^{8}$. Nesse caso, durante sua concepção e posteriores revisões, é que serão decididos os investimentos que a organização deverá realizar no período

\footnotetext{
8 No caso do setor público federal, o planejamento estratégico recebe o nome de estratégias nacionais de desenvolvimento.
} 
planejado, bem como a manutenção, o início ou a exclusão dos itens de custeio. A partir da consolidação dessas premissas é que o orçamento operacional poderá ser esboçado.

A projeção do orçamento envolve todos os níveis hierárquicos de uma instituição, o que permite uma ampla discussão dos objetivos que se deseja alcançar. Dessa forma, ocorre um crescimento da integração e do comprometimento dos colaboradores, dado haver um amplo envolvimento com os resultados planejados. Ao elaborar o orçamento, a empresa tem em mãos um instrumento de tomada de decisão, cujo objetivo é a apresentação de seu programa orçamentário, bem como do esclarecimento de suas normas e procedimentos que visam regular a instituição (ZDANOWICZ, 1986).

A partir dessas definições, o orçamento pode passar por algumas grandes etapas, aqui sugeridas em número de nove:

- Etapa 1: concepção ou revisão do planejamento estratégico, no tocante a definição de investimentos e custeio;
- Etapa 2: aprovação das premissas para receita, despesas e investimento e definição dos responsáveis por áreas;

- Etapa 3: reunião com gerentes e chefias para abertura dos trabalhos do orçamento;

- Etapa 4: preenchimento das planilhas de receita e custeio pelos responsáveis por área, validado pelo diretor da área;

- Etapa 5: preenchimento das planilhas de investimento pelos responsáveis por área, validado pelo diretor da área;

- Etapa 6: consolidação e rodadas de reuniões individuais com responsáveis pelas áreas;

- Etapa 7: aprovação do orçamento e projeção do balanço pela diretoria;

- Etapa 8: aprovação do orçamento e projeção do balanço pelo conselho de administração;

- Etapa 9: comunicação à empresa. 
Durante a Etapa 2 são aprovadas os princípios para receita, despesas e investimento. Ou seja, nesse momento são estimados o percentual de correção dos contratos dos clientes e fornecedores da companhia, tendo como base indicadores inflacionários de mercado como o Índice Geral de Preços de Mercado (IGP-M), o Índice de Preços ao Consumidor Amplo (IPCA) e o Índice Nacional de Preços ao Consumidor (INPC), ou através da adoção de uma planilha interna de custos; o percentual do crescimento vegetativo dos contratos; bem como se haverá possibilidade de aporte de capital. Além disso, adota-se uma previsão para a taxa de reajuste nos salários - a título de dissídio coletivo da categoria -, promoções, incremento de colaboradores e acordo com clientes inadimplentes.

Ainda nessa etapa são definidos os responsáveis por áreas. Os indicados tornam-se reguladores de todas as transações financeiras pertencentes às planilhas sob sua guarda, independente de o setor da empresa que a estiver reivindicando. Como ilustração pode-se citar o investimento em software, gerenciado pelo setor responsável pela administração de programas de computador. Todo o software adquirido pela companhia deverá estar previsto nessa planilha. Já a reunião geral com gerentes e chefias marca a abertura dos trabalhos do orçamento, abrangendo a Etapa 3.

As Etapas 4 e 5 envolvem o preenchimento, rubrica por rubrica, dos valores a serem despendidos ou arrecadados nas planilhas de receita, custeio e investimento pelos responsáveis por área. Após seu referido preenchimento, as mesmas devem ser validadas pelo diretor de cada área. Ao final dessas fases, surge a Etapa 6, onde reuniões individuais com responsáveis pelas planilhas, capitaneadas pelo setor de coordenação ou planejamento, consolidam o orçamento, arredondando os últimos entraves.

Por fim, ocorre a aprovação do orçamento e a projeção do balanço por parte da diretoria (Etapa 7), pelo conselho de administração (Etapa 8) e, finalmente, a comunicação para toda a companhia (Etapa 9).

\subsection{Operacionalização}

Uma vez implementado, o orçamento passa a ser controlado. Essa tarefa pode ser atribuída ao setor 
financeiro. Para tanto, pode-se empregar uma planilha eletrônica, cujo conteúdo é uma réplica do orçamento.

Quando surge uma necessidade de dispêndio, o solicitante - que pode ser um colaborador da empresa ou até mesmo um setor - confecciona um processo ou uma requisição interna, que segue um trâmite dentro da companhia, recebendo a aprovação do gestor responsável pela área que contempla o objeto solicitado, bem como do setor de compras. Superada essa etapa, o processo ou requisição é remetido à função administrativa de controle (ZDANOWICZ, 1986), que analisa se o documento está correto, com as informações de planilha e rubrica a serem averiguadas. $\mathrm{Na}$ hipótese das informações estarem incorretas ou inexistirem, o processo ou rubrica retorna à sua origem para que tais informações sejam contempladas. Todavia, se estiverem certas e houver saldo existente na rubrica em relação ao valor requisitado, o processo ou requisição recebe um parecer de aprovação e segue seu caminho natural, rumo à análise do controller da companhia e, posteriormente, ao órgão que autoriza o dispêndio. Caso contrário, o parecer aponta a necessidade de indicação de origem da receita. Nesse particular, o processo ou requisição retorna ao gestor responsável pela planilha em análise, que indicará de onde virá o recurso.

Por outro lado, quando a solicitação não representa um gasto imediato, mas sim uma autorização para fazê-lo no futuro - como um registro de preços - deve ser feita através de um processo, necessariamente, não indicando a dedução do saldo de qualquer rubrica.

\subsection{Consolidação}

Confrontam-se os valores previstos com os realizados, no caso da despesa, e com os faturados, se estiver tratando de receita. Ou seja, verificam-se os resultados alcançados em relação aos propostos (ZDANOWICZ, 1986). Caso ocorram distorções significativas, devem-se buscar suas causas para futuras correções.

Em relação à receita, se forem apurados valores faturados fora de sintonia com os previstos, torna-se imperioso saber se houve conservadorismo demasiado ou otimismo exacerbado na previsão, ou 
ainda, se ocorreu um crescimento significativo do número de contratos celebrados junto aos clientes no transcorrer do exercício. Já no caso da despesa, caso sejam constatadas distorções, as mesmas podem ter ocorrido por maximização ou minimização das despesas previstas, ou pela incidência de situações que remetem à anormalidade, como a quebra de um equipamento por motivos temporais ou catástrofes naturais, ou ainda por oportunidade de negócios novos que trarão receita à organização. Todavia, deve-se ter em mente que o orçamento operacional deve sempre apresentar a menor margem de erro possível.

\section{Avaliação dos Benefícios e Custos}

\section{na Adoção do Orçamento Operacional}

A avaliação dos benefícios e dos custos da adoção do orçamento operacional por parte de uma organização pode ser feita através da análise de alguns fatores diretos $\mathrm{e}$ indiretos. Um controle mais estreito das receitas e das despesas, onde as primeiras devem superar ou igualar às últimas, é um exemplo de um benefício direto. Assim, benefício direto consiste do valor dos bens ou serviços obtidos com o projeto, em comparação com os resultados sem o projeto. Nas palavras de McGuigan, Moyer e Harris (2004, p. 455):

$$
\begin{aligned}
& \text { [...] benefícios } \\
& \text { primários ou } \\
& \text { indiretos de um } \\
& \text { projeto podem ser } \\
& \text { considerados } \\
& \text { como o valor total } \\
& \text { que os usuários } \\
& \text { pagam (supondo a } \\
& \text { competição pura) } \\
& \text { ou que estariam } \\
& \text { dispostos a pagar } \\
& \text { (receita total em } \\
& \text { caso de haver um } \\
& \text { encargo, acrescida } \\
& \text { de um excedente } \\
& \text { do consumidor } \\
& \text { quando não } \\
& \text { prevalece a } \\
& \text { competição pura). }
\end{aligned}
$$

Já a estimativa dos custos diretos tende a ser mais fácil na comparação aos benefícios diretos. Isso ocorre porque custos diretos incluem os custos de capital necessários para a confecção do projeto (no caso, a elaboração de um orçamento operacional), os custos operacionais e de manutenção surgidos durante sua vida útil, as despesas com pessoal envolvido, além dos custos de oportunidade. A mensuração dos citados custos remete a menor dificuldade quando se trata de bens tangíveis como 
máquinas, equipamentos e automóveis, em relação a investimentos em sistemas, como é o caso de um orçamento operacional. Além disso, há os custos e benefícios indiretos. Tais grandezas podem refletir dois efeitos: efeitos reais ou tecnológicos e efeitos pecuniários (McGUIGAN et al., 2004).

Os benefícios reais indiretos podem ser constatados quando a execução de um projeto remete à redução nos desembolsos necessários para outros projetos. No caso do orçamento operacional, isso pode verificado quando o controle das finanças permite a realização de mais projetos na instituição, trazendo uma maior rentabilidade à mesma. Já os custos reais indiretos são aqueles que não estão diretamente ligados ao projeto original. Um exemplo disso são os maiores custos contratuais causados por um maior número de projetos em andamento na organização, devido à já mencionada externalidade positiva proporcionada pela adoção de um orçamento operacional. Isso ocorre, pois dada uma lógica de governança, o número de contratos da instituição cresce à medida que aumentam o número de projetos (WILLIAMSON, 1985; McGUIGAN et al., 2004).

Os benefícios e custos pecuniários geralmente não estão incluídos na avaliação do custobenefício em um projeto em fase de elaboração. Em função de sua natureza, surgem sob forma de custos de insumos mais baixos, volumes aumentados de negócios e multas contratuais. Por sua natureza, são puramente distributivos sendo difícil sua mensuração (McGUIGAN et al., 2004).

Por fim, mencionam-se os benefícios e custos intangíveis. Para esse grupo, calcular o valor de uma unidade monetária torna-se difícil ou quase impossível. Os intangíveis podem abranger: qualidade de vida, contribuições ou danos estéticos e impactos no balanço da organização. Devido a sua especificidade, seus benefícios podem ser pecuniariamente apenas relacionados com estimativas de ganhos. Nesse particular, contudo, seus custos não podem ser determinados. McGuigan, Moyer e Harris (2004) sugerem, como alternativa, que tais custos sejam conectados aos bens tangíveis, de tal forma que o custo dos incrementos adicionais intangíveis possa 
ser associados aos benefícios tangíveis abandonados de um projeto.

\section{Considerações Finais}

$\mathrm{O}$ orçamento pode ser conceituado como uma ferramenta de planejamento e controle com vínculos estreitos com a produtividade e a política de investimentos da organização. Seu objetivo principal é a maximização do rendimento dos recursos físicos $\mathrm{e}$ monetários. Existe uma intrínseca relação entre o planejamento $\mathrm{e} o$ controle. Sem um efetivo planejamento não poderá haver controle real. Da mesma forma, sem controle efetivo não haverá planejamento.

Desde o surgimento do orçamento tradicional, em 1822, passando pela sua adoção pelas empresas privadas, no início do século $\mathrm{XX}$, e chegando ao modelo atual, como função de instrumento administrativo, após a revolução keynesiana da década de 1930, o orçamento - enquanto ferramenta administrativa - passou e continua passando por constantes aprimoramentos. No Brasil isso por ser constatado pela elaboração do plano plurianual (PPA), da lei de diretrizes orçamentárias (LDO) e dos orçamentos anuais, contemplados e complementados no Orçamento Geral da União (OGU), e pela Lei de Responsabilidade Fiscal (LRF).

Muitas organizações adotaram e vem aprimorando o orçamento operacional no interior de suas esferas, cujo formato poderá variar de acordo com o tamanho da instituição. A citada adoção do orçamento operacional remete a ganhos que podem ser apurados através da avaliação dos benefícios e dos custos trazidos à organização. Isso pode ser feito através da análise de fatores diretos e indiretos. Enquanto benefícios diretos consistem do valor dos bens ou serviços obtidos com o projeto, em comparação com os resultados sem o projeto, custos diretos provêm dos dispêndios necessários para que o projeto saia do papel, sendo aí incluídos os custos de oportunidade. Por sua vez, os custos e benefícios indiretos refletem efeitos reais ou tecnológicos e efeitos pecuniários. Além deles, há ainda os custos e benefício intangíveis.

Por fim, cabe referenciar que sob os efeitos de uma volatilidade do mercado causados por uma crise econômica mundial ainda não totalmente debelada, a empregabilidade de um 
orçamento operacional torna-se
imperiosa por parte de qualquer
instituição, independente de seu
tamanho. Porém, devido ao diferenciado
aprofundamento que possa alcançar em
cada organização que o implemente,
reconhece-se o caráter limitado da
análise aqui realizada.

\section{Referências}

FUROBOTN, Eirik G.; RICHTER, Rudolf. Institutions and economic theory. The contribution of the new institutional economics. The University of Michigan Press. 2000. Disponível em: <http://books.google.com.br/books?id=B MWR1kaoThAC\&dq=Institutions+and+ economic+theory

.+The+contribution+of+the+new+institu tional+economics\&printsec $=$ frontcover $\&$ source $=$ bn $\&$ hl $=$ pt -

BR\&ei=f10VSsiCGoHAtwei9Y37DA\& $\mathrm{sa}=X \&$ oi=book_result\&ct=result\&resnu $\mathrm{m}=4 \#$ PPA496,M1>. Acesso em: $13 \mathrm{abr}$. 2009.

MACHADO, Nelson. Sistema de informação de custo: diretrizes para integração ao orçamento público e à contabilidade governamental, 2002, p. 1-16; 118-157.

MCGUIGAN, James; MOYER, R. Charles; HARRIS, Frederick H. de B. Economia de empresas: aplicações, estratégia e táticas. Thomson Pioneira Editora, 2004. Cap. 12.

PÁGINA CIDADES. Delfim defende déficit nominal zero para redução dos juros. Jornal O Estado de São Paulo. São Paulo, 24 de mar. 2005. Disponível em:

http://www.estadao.com.br/arquivo/econ omia/2005/not20050324p6900.htm>.

Acesso em: 10 de nov. 2005.

VASCONCELLOS, Marco A. S. de; GARCIA, Manuel E. Fundamentos de economia. $3^{\text {a }}$ ed. São Paulo: Saraiva, 2008, páginas: 233-247.

WILLIAMSON, Oliver. E. The mechanisms of governance and management. London: Oxford University Press: 1985

ZDANOWICZ, José E. Casos de administração financeira e orçamento: memórias de um professor. Porto Alegre: Sagra Luzzatto, 1986 